\title{
Calidad, ideología y paz: un estudio cualitativo sobre el Centro de Conciliación IPRECON y la conciliación extrajudicial en el Perú
}

Joss Brian Opie

\section{Introducción}

La institución de la Conciliación Extrajudicial fue establecida en el Perú el 13 de noviembre de 1997. Desde entonces, muchos nuevos actores sociales han surgido vinculados a ella, como conciliadores, centros de conciliación y centros de capacitación. También, se han publicado muchos artículos y estudios sobre la conciliación. Sin embargo, hasta ahora no se ha realizado un estudio cualitativo sobre la calidad del servicio de un centro de conciliación.

Debido a esta ausencia de trabajo cualitativo de campo sobre esta nueva institución de conciliación, y la necesidad de ello, el Instituto Peruano de Resolución de Conflictos, Mediación y Negociación' (IPRECON) decidió evaluar la calidad de su servicio conciliatorio. Tres objetivos fueron formulados para la investigación. El primero es discutir qué significa "calidad» en la conciliación, ${ }^{2}$ el segundo es determinar si el IPRECON brinda un servicio conciliatorio de calidad y el tercero es identificar elementos para una mejor implementación de la conciliación en el Perú.

IPRECON esperaba que tal investigación le daría la oportunidad de reflexionar sobre la calidad de sus intervenciones en los conflictos de sus clientes y cómo mejorar estas intervenciones y evitar o reducir errores. Además, IPRECON tiene una fuerte inquietud sobre la creciente pérdida

1 IPRECON es una organización formada en 1992. Es pionera en el Perú en el estudio y práctica de los MARC.

2 "La Conciliación" en este documento (salvo dicho lo contrario) se refiere a la conciliación extrajudicial tal como fue establecida por la Ley No 26872 (Ley de la Conciliación). 
de prestigio de la conciliación como una alternativa viable al congestionado sistema judicial. Por lo tanto, IPRECON no solo espera que este documento lo ayude en la evaluación de su servicio, sino que también fomente un nuevo debate y discusión sobre la conciliación entre los otros operadores y servicios conciliatorios, y tal vez nuevas revelaciones sobre la dirección que debería tomar en el futuro.

Para cumplir los tres objetivos descritos arriba, el documento es dividido en cuatro secciones. La primera sección describe el contexto en el cual IPRECON brinda su servicio conciliatorio. La segunda sección discute el concepto de "calidad» en la conciliación y la definición de IPRECON sobre calidad. La tercera sección presenta metodología y resultados de entrevistas hechas con clientes de IPRECON. La cuarta sección manifiesta conclusiones sobre la calidad del servicio IPRECON. Una conclusión cita que la estructura legal establecida para la conciliación es insuficiente para asegurar calidad, y se recomienda redactar un documento de discusión, con la meta de desarrollar la conciliación en Perú.

\section{El contexto}

En esta sección damos una descripción breve de IPRECON y los problemas actuales que enfrenta la conciliación en el Perú. Luego presentamos un resumen de la Ley No 26872- la Ley de la Conciliación ("la ley») y sus Reglamentos: el reglamento de la Ley de la Conciliación DS No 001-98-JUS modificado por DS No 016-2001-JUS («el reglamento») y el reglamento de sanciones a conciliadores, centros de la conciliación, y centros de formación y capacitadores RM No 245-2001-JUS («el reglamento de sanciones»).

\subsection{IPRECON y el estado actual de la Conciliación extrajudicial}

IPRECON es un centro de conciliación ubicado en San Isidro, Lima. Ha trabajado en resolución de conflictos desde 1992, y fue autorizado a ejercer como centro de conciliación según lo establecido por la ley en noviembre de 1998. Cuenta con tres conciliadores permanentes. Dos de ellos son abogados, y el tercer es psicólogo. También cuenta con tres conciliadores «flotantes». 
Actualmente, hay una preocupación muy difundida entre miembros de la comunidad legal y conciliatoria sobre la calidad (o la falta de ella), de los conciliadores y capacitadores en conciliación en el Perú. El Instituto de Defensa Legal describe a la conciliación como una institución asediada por los problemas sociales del Perú, con el resultado que el proceso se ha vuelto "bastante distorsionado" ${ }^{3}$ y su operación empírica está muy lejos de la institución prevista por la ley.

Uno de los problemas sociales más significativos afectando la institución es el alto nivel de desempleo y subempleo en el Perú. Muchas personas, especialmente abogados, ven a la conciliación como una fuente de trabajo muy necesario. Así, el número de centros de capacitación, centros de conciliación, y conciliadores ha crecido exponencialmente desde el principio de la ley. Actualmente, hay alrededor de once mil conciliadores acreditados y cuatrocientos sesenta y un centros de conciliación. ${ }^{4}$ Sin embargo, el Ministerio de Justicia (la entidad reguladora del sistema conciliatorio) no ha recibido fondos públicos para regular la institución de la conciliación. La carencia inicial de normas contribuyó a prácticas como el cobro de tasas diferentes si se logran o no un acuerdo y tasas sumamente bajas cobradas por conciliadores desesperados por conseguir trabajo. Estos fallos contribuyen a una erosión general de la imagen de la conciliación en el Perú.

\subsection{La ley y sus reglamentos}

La obligatoriedad del sistema conciliatorio existe en forma limitada en Lima Metropolitana y Callao, la ciudad de Arequipa y la ciudad de Trujillo (se la puso en marcha en esta ciudad desde el $1^{\circ}$ de marzo de 2001). La ley y sus reglamentos pueden ser vistos como los instrumentos críticos en la definición y reglamento de «la conciliación de calidad» en el Perú. Crean ciertos estándares de práctica que conciliadores, centros de conciliación y centros de capacitación están obligados a seguir, y un régimen que tiene el poder de sancionar a los que falten al cumplimiento de estos estándares.

Discutimos brevemente la definición de la conciliación que brinda la ley, los principios que expone, los tipos de conflictos que están sujetos a la

3 Instituto de Defensa Legal, Cambios en la Justicia Peruana y Sociedad Civil (19902002) Borrador, 2002, p 27.

4 Instituto de Defensa Legal, op. cit., p 29. 
ley, la naturaleza de la obligación a solicitar la conciliación cuando surjan estos tipos de conflictos, el valor jurídico de cualquier acuerdo conciliatorio, y los deberes del conciliador. También mencionamos el rol del Ministerio de Justicia y el régimen de sanciones a los operadores del sistema conciliatorio de incurrir en infracciones a las normas.

"La conciliación» es definida en el artículo $5^{\circ}$ de la ley como: «un mecanismo alternativo para la solución de conflictos, por el cual las partes acuden ante un Centro de Conciliación [...] a fin que se les asista en la búsqueda de una solución consensual al conflicto.» $\mathrm{El}$ artículo $1^{\circ}$ declara que es «de interés nacional la institucionalización y desarrollo de la conciliación". La conciliación es descrita como un mecanismo que "propicia una cultura de pazm. 5

El artículo $2^{\circ}$ establece los principios en los cuales la institución de la conciliación es fijada. Son equidad, veracidad, buena fe, confidencialidad, imparcialidad, neutralidad, legalidad, celeridad y economía. El reglamento clarifica el significado de los principios. Por ejemplo, el artículo $2^{\circ} \mathrm{del}$ reglamento expresa que la veracidad es la idea que las partes llegarán a un acuerdo de manera libre, y además, que la solución será «la mejor solución para ambas». El artículo $3^{\circ}$ de la ley es también importante y señala que la conciliación es una «institución consensual», es decir que cualquier acuerdo que consigan las partes será exclusivamente producto de su voluntad.

El artículo $6^{\circ}$ de la ley enuncia las situaciones en las cuales no se puede recurrir a la conciliación. Una de las excepciones más notables es la violencia familiar. Originalmente, estos casos podían estar sujetos a la conciliación, pero eso fue modificado radicalmente por la Ley No 27398 del 13 enero del 2001.

Alternativamente, el artículo $9^{\circ}$ de la ley establece las materias que sí pueden ser sujetas a la conciliación. Las materias son los conflictos relacionados con derechos disponibles, como disputas contractuales, pleitos sobre deudas y otros de contenido patrimonial y desalojo. Los asuntos familiares relativos a alimentos, régimen de visitas y tenencia también son conciliables, al igual que los asuntos laborales.

$\mathrm{El}$ artículo $6^{\circ}$ de la ley ordena que el procedimiento conciliatorio es un requisito de admisibilidad para los procesos a que se refiere el artículo 9». Esto significa que cuando sea aplicable el artículo $9^{\circ}$, la conciliación debe ser agotada por las partes antes de iniciar un proceso judicial. Así, si

5 El artículo $2^{\circ}$ de la ley. 
cualquiera de las dos partes no asiste a dos de las sesiones conciliatorias planeadas, o si las dos no asisten a una, la conciliación será dada como "concluida». ${ }^{6}$ Entonces, cualquier parte puede iniciar un proceso judicial. ${ }^{7}$ Por lo tanto, aunque hay un elemento obligatorio en la conciliación, la obligación es débil puesto que no requiere que las partes asistan la audiencia.

La ley contempla que las partes formalicen cualquier acuerdo que se consigne en un acta. Esta, salvo que no se adecue a los requisitos del artículo $16^{\circ}$ de la ley, tendrá el valor de un título de ejecución, lo cual tiene efectos similares al de una sentencia judicial firme.

El artículo $31^{\circ}$ del reglamento expresa los deberes del conciliador. Requiere que el conciliador informe a las partes sobre la conciliación, su naturaleza, características, fines y ventajas en la primera reunión. Durante la audiencia, el conciliador facilitará el diálogo entre las partes, tratará de ubicar el interés de cada una, identificará el o los problemas centrales entre las partes, y enfatizará los intereses comunes entre ellas. Si lo estima conveniente, sugerirá fórmulas conciliatorias a las partes. El artículo $31^{\circ}(11)$ también requiere que el conciliador informe a las partes sobre "el alcance y efectos" del acta antes de su redacción final.

El artículo $32^{\circ}$ de reglamento dicta que el conciliador debe desarrollar un procedimiento que asegure que las partes puedan participar en la conciliación libre de presiones. El conciliador se comportará objetivamente, y se dirigirá al logro de un acuerdo «satisfactorio para ambas partes».

\subsubsection{El Ministerio de Justicia}

El Ministerio de Justicia tiene un rol sumamente importante en el sistema conciliatorio peruano. La ley lo designa como el encargado de autorizar, registrar, supervisar y sancionar a todos los conciliadores, capacitadores, centros de conciliación y centros de capacitación que hayan sido registrados y autorizados para operar dentro del sistema.

$\mathrm{El}$ artículo $7^{\circ} \mathrm{del}$ reglamento de sanciones muestra varias sanciones que puede imponer el ministerio. Puede asignar amonestaciones escritas,

$6 \mathrm{El}$ artículo $15^{\circ}$ de la ley también declara que se dará la audiencia por concluida por acuerdo total o parcial de las partes, o por falta de acuerdo. El Artículo $17^{\circ}$ del reglamento enuncia que el conciliador puede dar por concluida la audiencia como parte de su «libertad de acción", instituido en el Artículo $21^{\circ}$ de la ley.

7 La Ley, el artículo $15^{\circ}$. 
suspensiones, y desautorizaciones de funcionamiento; y a los centros de conciliación, imponer multas, suspensiones de un mes a un año, e inhabilitaciones permanentes.

El reglamento de sanciones tiene una lista detallada de las circunstancias en las cuales se aplican las sanciones. Por ejemplo, «la inobservancia grave e inexcusable de alguno de los principios» ${ }^{8}$ implicará suspensión. La inhabilitación permanente será impuesta cuando haya "violación grave e inexcusable de los principios de confidencialidad, neutralidad o imparcialidad, en perjuicio de las partes o tercerosm.?

\section{Calidad en la conciliación}

En esta sección revisamos códigos de conducta internacionales y definiciones académicas de calidad sobre mediación, ${ }^{10} \mathrm{y}$ también señalamos que no hay una "definición clave» de calidad. Luego comparamos los estándares internacionales de mediación con la ley y el reglamento, destacando áreas de incertidumbre y trazando lo que observamos como los presupuestos dominantes de la ley. Después, exponemos la definición de IPRECON sobre calidad, y hacemos una discusión de sus características distintivas.

\subsection{Los estándares internacionales de mediación}

No hay una definición universal de "calidad" ni en la conciliación o en el campo general de los medios alternativos para la resolución de conflictos (MARC). En realidad, el tema es muy discutido y sujeto a múltiples interpretaciones diferentes que tienen prioridades conflictivas. Sin embargo, aunque no podemos recurrir a una definición única, hay numerosos puntos de coincidencia entre los indicadores de calidad identificados en estándares, pautas y textos académicos. Estos indicadores nos dan un punto de partida para desempeñar una evaluación de un servicio de algún MARC; en este caso, un servicio conciliatorio.

8 Reglamento de sanciones, artículo $14^{\circ}(1)$.

9 Reglamento de sanciones, artículo $17^{\circ}(4)$.

10 Para efectos de este artículo los términos «mediación" y «conciliación» son tomados como sinónimos por compartir características muy similares. 
Sin embargo, tenemos que diferenciar entre los artículos académicos y los códigos y las pautas de conducta en conciliación o mediación. Los códigos y las pautas se relacionan, casi exclusivamente, con el reglamento de las interacciones entre las partes y el profesional. Tienden a establecer requisitos mínimos que tienen que ser cumplidos en la provisión de servicios de los MARC; por ejemplo, el requisito que el conciliador sea imparcial. Por lo tanto, es implícito que un servicio de calidad sea aquel que cumple con todos los requisitos mínimos.

Por otra parte, los textos académicos desarrollan definiciones o estándares de calidad que son aun más amplios. No son solo requisitos mínimos como la imparcialidad y confidencialidad, sino que incluyen también objetivos diversos como la satisfacción individual, el fortalecimiento de la comunidad o el desafío a las relaciones de poder. El valor de los objetivos no es fijado sino indeterminado y, por eso, la prioridad que se da a cada objetivo depende del contexto y la ideología de la institución que provee el servicio de algún MARC. Los objetivos pueden ser incluso contradictorios: por ejemplo, el objetivo de satisfacción individual podría limitar la posibilidad de realizar el objetivo de redistribución del poder en la sociedad.

El campo de investigación es, por lo visto, mucho más amplio que aquello señalado en las pautas o los códigos. No está limitado a las interacciones entre las partes y el profesional, sino se trata de considerar también los efectos de las instituciones MARC en la comunidad y/o la sociedad. En efecto, en algunos casos, estos asuntos son colocados como metas del servicio MARC. Así, la calidad de tal servicio será medida según cuanto el servicio realice o contribuya a la meta fijada previamente.

Eso no quiere decir que los códigos y pautas no sean representaciones de ciertos discursos o presupuestos políticos de aquellas instituciones que los elaboran. Es claro que lo son, en el sentido explícito y también por omisión. Por ejemplo, ¿qué deberíamos pensar del hecho que pautas como los Estándares de la Comisión de Georgetown (CPR-Georgetown Commission on Ethics and Standards of Practice in $A D R$ ) hayan incluido una exhortación a los profesionales en MARCs para que aumenten la accesibilidad, pero por otro lado no poseen un estímulo similar que, por ejemplo, produzcan cambio institucional? 


\subsubsection{Los códigos y las pautas}

Los códigos y las pautas tienen algunos requisitos mínimos en común, aunque el contenido sustantivo de ciertos requisitos puede variar. Estos son, por ejemplo, autonomía individual, ${ }^{11}$ consentimiento informado, ${ }^{12}$ confidencialidad, imparcialidad, neutralidad, y competencia del conciliador. ${ }^{13}$ Los intereses de terceros no representados tienen que ser considerados, cuando sean afectados. Debe haber procesos de queja establecidos, en conocimiento de las partes, y también ciertos requisitos establecidos para el "marketing" del servicio y la revelación de los detalles de los honorarios de los conciliadores. La reducción de costos de las partes (tiempo, dinero y costo psicológico) es un criterio importante. También, el Consejo Consultivo Nacional de Resolución Alternativa de Conflictos de Australia (NADRAC) y la Sociedad de Profesionales en Resolución de Conflictos de los EUA (SPIDR) por ejemplo, consideran que los profesionales en MARC tienen un deber que cumplir en el aumento de la

11 Las partes asisten voluntariamente en el proceso y llegan a la resolución (si hay resolución) sin coacción cualquiera del conciliador, de la otra parte, o de terceros. Puede verse en las pautas Oregon Mediation Association Draft Standards of Practice, 2000, Core Standard 1, Self Determination. Ver página web: www.mediate.com/articles/orstdsd.cfm

12 El conciliador tiene que asegurar que las partes comprendan el proceso: sus beneficios, costos y riesgos, y los derechos de las partes en el proceso (por ejemplo el derecho de terminar la Conciliación cuando quieran), los procedimientos del proceso, el rol del conciliador y la relación de las partes al conciliador. Una referencia es los Estándares Eticos de SPIDR (1986 SPIDR Ethical Standards of Professional Responsibility) Párrafo $2^{\circ}$ de la SPIDR. Ver página web: www.spidr.org/. Un asunto bastante discutido en la bibliografía es si el conciliador necesita asegurar que cualquier resultado de las partes sea informada. El rol del conciliador en esta situación y los problemas con la idea de consentimiento informado serán tratados más adelante.

13 El NADRAC dice que los profesionales competentes en MARCs son: Buenos comunicadores, con experiencia y conocimiento de ellos mismos y de temas como conflicto, cultura, negociación, contexto, procedimientos, y MARC. Son capaces de valorar el pleito, definir los asuntos, manejar el proceso y la interacción de las partes, asegurar participación efectiva de ambas partes, alentar a las partes para que negocien, mantener la confidencialidad y ser imparcial y neutral, capaz de asegurar resultados apropiados (a las partes, terceros, y la sociedad en general), capaz de tomar decisiones y concluir la Conciliación si no habrá posibilidad de acuerdo, y/o las partes están abusando del proceso, y capaz de concluir el proceso (llegar a un resolución). NADRAC A Framework for ADR Standards (2001) párrafo 10 29. Ver página web: www.law.gov.au/aghome/advisory/nadrad frameworkfiles.htm. 
provisión de los servicios de conciliación a todos los sectores de la sociedad, a través de diversos métodos como los servicios gratuitos.

\subsubsection{Definiciones académicas de calidad}

Baruch-Bush ha formulado seis estándares comprensivos de calidad, que incorporan una amplia selección de asuntos a través de divisiones ideológicas. ${ }^{14}$ Como hemos explicado previamente, algunos de los estándares son contradictorios y no representan categorías cerradas, ni son siempre mutuamente excluyentes. En algunos casos, factores que son relevantes a un estándar también son relevantes a otros. Los estándares son: satisfacción individual, ${ }^{15}$ autonomía individual, ${ }^{16}$ control social, ${ }^{17}$ justicia social, ${ }^{18}$ solidaridad social ${ }^{19}$ y transformación personal. ${ }^{20}$ NADRAC también dice que los resultados de procesos MARC deben ser aceptables, ${ }^{21}$ duraderos, flexibles y creativos.

14 Robert A Baruch Bush, "Defining Quality in Dispute Resolution: Taxonomies and Anti-Taxonomies of Quality Arguments", en: Denver University Law Review Vol. 66, No 3,1989 , p. 335.

15 Todas las definiciones que a continuación presentamos provienen de Baruch Bush, op. cit., p. 349. No hay intención que sean exhaustivos. Algunos indicadores importantes de satisfacción individual son: las partes se sienten que fueron escuchadas; las partes tienen el derecho de escoger si participan o no del proceso; las partes participan directamente; el proceso tiene un efecto positivo en la relación de las partes; las partes no sienten que el resultado favorece demasiado a la otra parte; se evita un proceso formal; se logran soluciones creativas; el conflicto es comprehensivamente resuelto; el resultado contiene a sus intereses y necesidades (definidos subjetivamente); las partes cumplen el acuerdo.

$16 \mathrm{El}$ proceso educa a las partes en destrezas de resolución de conflictos, el proceso o resultado potencia a las partes, y ellas ejercen control sobre el proceso y el resultado.

$17 \mathrm{El}$ proceso o resultado reduce conflicto social (posiblemente de una manera que sirva a intereses políticos dominantes).

18 No hay ventaja de una de las partes en el proceso, el proceso no es dañoso a la parte menos pudiente, el proceso asegura acceso a los ricos y a los pobres igualmente, el resultado produce cambio institucional, el proceso alienta el comportamiento decente, el proceso potencia a las mujeres o a otros grupos desaventajados y el resultado no dañe al interese público.

$19 \mathrm{El}$ procedimiento fortalece a la comunidad, y el resultado es determinado por normas legales.

20 El proceso estimula el crecimiento personal de las partes, hace que las partes reconozcan o aprecien la situación de la otra parte, facilita la expresión de emociones, hace que las partes sean más honestas y abiertas con la otra parte y con uno mismo.

21 A las partes, a los terceros, y a la sociedad en general. 
2.2. Comparaciones entre la ley y los estándares internacionales de mediación

Aunque los códigos, las pautas y las definiciones académicas no estén siempre de acuerdo, es todavía posible hacer comparaciones entre ellos y la ley y el reglamento (que contienen algunos estándares actuales de calidad en la conciliación en el Perú.). En la próxima sección desempeñamos esta tarea, con el objetivo de exponer los presupuestos dominantes de la ley, y resaltar diferencias entre la estructura legal peruana y los estándares internacionales de mediación.

\subsubsection{Presupuestos dominantes de la ley}

Los presupuestos dominantes que vemos en la ley y el reglamento son: libertad de elección, autonomía individual y confianza en la habilidad de las partes de actuar racionalmente. La ley confía que a través de la estructura establecida por sus principios las partes elegirán los acuerdos que sean "satisfactorios para ambas». ${ }^{22}$ La ley y el reglamento prevén, aparentemente, un procedimiento en el cual individuos, que son racionales y están adecuadamente informados, participan igualmente para llegar a un acuerdo que aproxime una concepción común del «bien». Aunque las partes puedan invitar a "personas de su confianza» para participar en la audiencia, ${ }^{23}$ como sus abogados o asesores, no están obligadas a hacerlo. Además, existen limitaciones especificas a esta participación, ${ }^{24}$ otra vez, con la intención de proteger la libertad de elección y la libertad de cualquier coacción de las partes y el conciliador.

\subsection{2 ¿Una cultura de paz?}

UNESCO declara que «cualquier cultura de paz es [...] una fuerza dinámica que pretende auxiliar la transformación por nosotros y en nosotros mismos de nuestros modelos de comportamiento y nuestras relacio-

22 El Artículo $32^{\circ}$ (2) del reglamento.

23 El Artículo $17^{\circ}$ del reglamento.

$24 \mathrm{El}$ Artículo $17^{\circ} \mathrm{del}$ reglamento dicta que el derecho de participar de las personas de confianza es limitado a la provisión de información dentro de su especialización para que asesore la parte involucrada para que ésta tome una decisión informada. 
nes con los demás». ${ }^{25}$ UNESCO brinda una definición comprehensiva de tal cultura ${ }^{26}$ y expresa que "la paz significa construir: no se puede inventarla de un momento a otro, sino que tiene que ser construida, día a día. Es una tarea que requiere una visión a largo plazom. ${ }^{27}$

En contraste, la ley no ofrece ninguna definición. Si bien es cierto que declara que la conciliación "propicia una cultura de paz", la ley asume que eso va a producirse al nivel de la sociedad a través de un tipo de proceso "filter-up" el resultado acumulativo de múltiples audiencias de conciliación en conformidad con los principios de la conciliación. En vez de la imposición de obligaciones particulares a las partes o al conciliador, (por ejemplo, que aprendan nuevas maneras de resolver conflictos) ${ }^{28}$ la ley solamente busca la edificación de una cierta relación entre las partes y el conciliador. Una "cultura de paz" será un resultado indirecto de estas interacciones; un efecto consecuente del ejercicio de la voluntad libre de las partes y sus decisiones autónomas, auxiliadas por un conciliador imparcial.

¿Será que la dependencia en conceptos, el individuo racional y la satisfacción de las partes sean suficientes para crear una cultura de paz o se tienen que tomar en cuenta otras variables? Por ejemplo, NADRAC razona que las identidades (género, raza, sexualidad y otras) «tienen un efecto poderoso en la manera que [la gente] reacciona a los conflictos" ${ }^{29}$

25 Federico Mayor y Jerome Binde, The World Abead: Our Future in the Making; UNESCO, París, 2001 , p. 459.

26 «Una cultura de interacción social y participación, basada en los principios de libertad, justicia y democracia, tolerancia y solidaridad; una cultura que rechace la violencia y se esfuerce por el prevenir de conflictos a través de abordarlos en sus raíces y resolver los problemas por el diálogo y la negociación; una cultura que garantice a todos el ejercicio completo de sus derechos y provenga los medios para que todos puedan participar en el desarrollo endógeno de su sociedad». Mayor y Binde, op. cit., p. 451.

27 Mayor y Binde, op. cit., p. 460.

28 Un ejemplo de un enfoque muy distinto a la creación de una cultura conciliatoria es el del Oregon Community Dispute Resolution Act. Este dicta que una meta de los programas de mediación en la comunidad será el fomento "[...] del desarrollo de programas basados en la comunidad que auxiliarán a los ciudadanos en la resolución de conflictos y el desarrollo de destrezas en resolución de conflictos [...]".Joseph B. Stulberg, "Fairness and Mediation", en: Obio State Journal on Dispute Resolution, Vol. 13, 1998, pp. 909-921.

29 NADRAC Issues of Fairness and Justice in Alternative Dispute Resolution: Discussion Paper ("Fairness and Justice») Canberra, NADRAC, 1997, p. 18. 
NADRAC argumenta también que es probable que las identidades de los individuos afecten su capacidad de participación en la mediación, y que resulta evidente que individuos menos poderosos ${ }^{30}$ tengan comprensiones muy distintas de sus derechos que los más poderosos. Así, los menos poderosos pueden «regatear por menos y arreglar por menos». ${ }^{31}$ Ambas partes puedan sentirse "satisfechas" con un acuerdo, si las aproxima a lo que ambas percibieron como una consecuencia posible de la conciliación. Sin embargo, esta "satisfacción" puede esconder un proceso en el que una de las partes no consiguió afirmarse efectivamente y, por eso, aceptó menos de lo que tal vez hubiera aceptado si hubiera estado en una posición de poder. "La paz» en términos de un cese del conflicto entre las partes se habría logrado, ¿pero cuál fue el costo de ella?

\subsubsection{Terceros no representados}

La ley, en su enfoque casi exclusivamente centrado en las partes, hace poco para proteger otros intereses, como los de terceros. Hay solamente dos referencias a los intereses de terceros en la ley y el reglamento. Una está relacionada con las excepciones al principio de confidencialidad. La otra está en el artículo $9{ }^{\circ}$ de la ley, que declara que "el conciliador tendrá en cuenta el interés superior del niño». No hay indicaciones del efecto que «el interés superior" debería tener en cualquier acuerdo que hagan las partes, y no se ve tampoco una obligación explícita impuesta en las partes que consideren el interés del niño. En comparación, los Estándares de Práctica de Familia (Association for Conflict Resolution Standards of Practice for Family and Divorce Mediation 1984 ) manifiesta que: ${ }^{32}$

«Responsabilidades hacia los terceros: El mediador tiene la responsabilidad de promover que los participantes consideren los intereses de niños y otras personas afectadas por el acuerdo. El mediador también tiene el deber de ayudar a los padres a evaluar, aparte de sus propios deseos, las necesidades separadas e individuales de dichas

$30 \mathrm{Un}$ individuo menos poderoso puede referirse a un empleado poco educado y pobre de un jefe de la compañía quien es rico y bien educado. NADRAC, Fairness and Justice., op. cit., p.19.

31 NADRAC, Fairness and Justice, op. cit., p.18.

32 Ver página web: www.acresolution.org/research.nsf/key/stand-prac. 
personas. Se sugerirá a las partes que busquen la asesoría independiente de profesionales cuando sea apropiado o cuando no sean capaces de ponerse de acuerdo sobre las necesidades de cualquier individuo afectado por el acuerdon.

Aunque esta provisión no impone obligaciones vinculadas a los participantes que incorporen los intereses de terceros en sus acuerdos, se va mucho más allá de la ley y el reglamento para tratar de asegurar que efectos más extensos, y posiblemente dañinos, de un acuerdo sean considerados. Como será tratado más adelante, es totalmente posible que un acuerdo sea "satisfactorio" para ambas partes, y a la vez tenga efectos negativos para terceros. Estos acuerdos, discutiblemente, no propician una cultura de paz: el mejor de los casos, el peso del conflicto recae en otro.

\subsubsection{Consentimiento informado}

Nadrac manifiesta que uno de los factores importantes para asegurar un "proceso justo" es que las partes «tengan acceso a toda la información relevante. ${ }^{33}$ SPIDR considera, en los Estándares Eticos de SPIDR (1986 SPIDR Ethical Standards of Professional Responsibility) que uno de los deberes del tercero hacia las partes es asegurar que su consentimiento sea informado. El párrafo $2^{\circ}$ de la sección «responsabilidades hacia las partes" declara: ${ }^{34}$

«El tercero tiene la obligación de asegurar que las partes entiendan la naturaleza del proceso, los procedimientos, el rol específico del tercero y la relación de las partes al tercero".

Este requisito es similar al del artículo $31^{\circ}(3)$ del reglamento. Algunas leyes van más allá para enunciar que el requisito del «consentimiento informadom se extiende al acuerdo: ${ }^{35}$

«El mediador auxiliará a las partes para que logren un acuerdo informado y voluntario».

33 NADRAC, Fairness and Justice., op. cit., p. 21.

34 SPIDR, op. cit.

35 Stulberg, op. cit., p. 936. 
Las justificaciones detrás de estos requisitos típicamente están relacionadas con preocupaciones sobre justicia y políticas públicas. La idea es garantizar que las partes no operen en ignorancia de sus derechos, sea en el proceso o en el acuerdo, puesto que dicha ignorancia podría socavar consideraciones de justicia u objetivos de políticas públicas. ${ }^{36}$

Nos gustaría dirigirnos a tres asuntos que surgen en este contexto. Todos tienen que ver con el asunto de estar informado sobre un acuerdo potencial. El primero es: ¿qué significa «informado", ¿cómo se puede concluir que una parte tiene toda la información relevante sobre un acuerdo potencial?. Otro es ¿̨cuánta información puede ofrecer el conciliador a las partes sin comprometer su imparcialidad?. El tercero se relaciona con ¿qué debe hacer el conciliador si cree que una de las partes, $o$ ambas, tomarán decisiones malas o no informadas?

Stulberg nos da una respuesta al primer asunto. Razona que «no hay un principio conceptual que pueda terminar la búsqueda de información adicional para tener certeza que una decisión sea informada». ${ }^{37}$ Por lo tanto, al menos en términos de decisiones sobre si uno acepte o no un acuerdo potencial, ${ }^{38}$ se tiene que aceptar que las partes nunca poseerán toda la información relevante. Sin embargo, como dice Stulberg, eso no es necesariamente preocupante. Se puede decir sobre cualquier decisión que tomemos que la decisión «no está tan informada como podría haber estado". ${ }^{39}$

Lo que sí es una preocupación válida, no obstante, es asegurar que las partes tengan acceso a la misma cantidad y/o calidad de información (al menos que eso sea posible). Otra vez surge un problema similar: ¡cómo

36 Por ejemplo, imaginemos un acuerdo según el cual una persona acepte un sueldo menor al sueldo mínimo, en ignorancia de sus derechos según las leyes laborales. Desde el punto de vista legal, tal acuerdo sería injusto, y también se podría decir que tal acuerdo socavará la política pública expresada en la garantía del sueldo mínimo.

37 Stulberg, op. cit., p. 942.

38 En nuestra opinión, es más fácil informar comprehensivamente a las partes sobre sus derechos en el proceso conciliatorio que en el acuerdo. Se puede ver el proceso como constante, mientras que las ramificaciones de los acuerdos siempre son más inciertas, especialmente cuando se considera el impacto de distintas interpretaciones de las normas aplicables. Pensando específicamente en el problema de la interpretación normativa, es mucho más fácil que el conciliador informe a las partes de sus derechos en el proceso sin comprometer su imparcialidad que informarles de los derechos legales que posiblemente tengan como consecuencia de la disputa.

39 Stulberg, op. cit., p. 942. 
se puede decir que tal criterio sea cumplido?. Stulberg expone que la respuesta es requerir que cada parte tenga asesoría legal y eso: ${ }^{40}$

"Crea el supuesto que cada persona tiene acceso a un recurso capaz [el abogado] que pueda proveerla con información apropiada. Evitamos el dilema de calidad desigual de asesoría como lo evita el sistema tradicional: por reconocer que el abogado puede proveer alguna, aunque no sea completa, información».

Lamentablemente, el enfoque de Stulberg también es muy problemático. Una de las fortalezas de los MARC es su potencial para evitar los costos de abogados, y la posibilidad que éstos tomen control del manejo del conflicto, así quitándoles a las partes la oportunidad de llegar a una solución independientemente.

Los Estándares de Práctica para los Mediadores de California (Standards of Practice for California Mediators) ${ }^{41}$ del Consejo de Resolución de Conflictos de California no van tan lejos como Stulberg en proponer que cada parte tenga asesoría legal. En «los estándares del manejo de la mediación" se dice que:

«El Mediador no debe dar al participante cualquier asesoría legal o profesional. El Mediador debe estimular a las participantes sin asesoría legal a que busquen independiente asesoría legal antes de firmar cualquier acuerdo legalmente vinculante».

Finalmente, los Estándares de Práctica de Familia declaran que: ${ }^{42}$

«Asesoría Independiente e Información: El mediador estimulará y auxiliará a los participantes para que obtengan información independiente y experta cuando dicha información sea necesaria para llegar a un acuerdo informado o para proteger los derechos de un participante».

Stulberg y casi todos ${ }^{43}$ concuerdan, que de acuerdo a los estándares y pautas mencionados que el profesional en MARC no debería ofrecer cual-

40 Stulberg. op. cit., p. 943

41 Ver página web http://www.conflict-resolution.net/cdrc/.

42 Los estándares de práctica de familia, op. cit., párrafo $8^{\circ}$.

43 Un enfoque un poco diferente es párrafo $6^{\circ}$ de los estándares éticos de SPIDR, $o p$. cit. Discuto esto en la página 14. 
quier asesoría sustantiva a las partes. Eso, en parte, contesta al segundo asunto: el tercero comprometería su imparcialidad si brindara asesoría substantiva. Sin embargo, nos queda una duda. ¿Qué tal si una parte rechaza el estímulo del tercero y resuelve no buscar asesoría independiente? En esta situación, ¿debería el tercero dejar que el acuerdo sea firmado, a pesar de la preocupación que tiene debido a que la decisión no es informada, o debería concluir la conciliación?

Los estándares éticos de SPIDR enuncia en el párrafo $6^{\circ}$ de la sección «responsabilidades hacia las partes" que:

«Si el tercero está preocupado por las consecuencias posibles de un acuerdo, y las necesidades de las partes así lo requieren, el tercero informará a las partes de su preocupación. Al adherirse a este estándar, el tercero podría educar a las partes, remitir a una o más partes a la asesoría especializada, o retirarse del caso".

Este estándar entonces permitiría al neutral "educar» a las partes, y también retirarse del caso. Como ya hemos mencionado, los conciliadores peruanos también tienen la opción de retirarse del caso, y así terminar la conciliación. No obstante, tal acción discutible, estaría fundamentalmente en contra de las ideas de autonomía de las partes y libertad de elección que promulga la ley. Tal comportamiento del conciliador podría ser considerado paternal y superior. Se puede imaginar muchas situaciones cuando este comportamiento del conciliador fuera visto como favoritismo de una parte sobre la otra.

No es nuestra tarea resolver estos asuntos, sino resaltarlos como preocupaciones. Lo que se tiene que notar es que la ley y el reglamento ofrecen al conciliador pautas muy pobres sobre su rol en el control de los términos del acuerdo. Además, aunque permiten que el conciliador termine la conciliación, no brindan recomendaciones de cuando eso debería ser hecho. Es necesario que la práctica en esta área sea consistente, para asegurar que las partes sean informadas, en el sentido explicado por Stulberg, y también para garantizar que la decisión del conciliador de acabar con la conciliación no sea vista como una acción arbitraria. Los criterios rígidos no son deseables (a causa del riesgo de que sean demasiado restrictivos de la libertad de acción del conciliador) pero la carencia total de criterios crea una posibilidad de que las partes sean expuestas a abusos, y/o que criterios enormemente distintos sean utilizados por los conciliadores basándose arbitrariamente en su libre discreción. 
Lo que es aún más importante tomando en cuenta el contexto peruano es que el artículo $16^{\circ}$ contempla: las partes analfabetas pueden vincularse a un acuerdo, imprimiendo su huella digital en el acta de conciliación. El analfabeto automáticamente queda en una posición de poder potencialmente muy desigual en relación a las partes que sí saben leer y escribir, especialmente si estas partes están asesoradas por abogados. En estas situaciones, es notablemente razonable que la parte analfabeta debería tener (o deberían darle), un representante que sepa leer y escribir ${ }^{44}$ para garantizar que el acta se ajuste plenamente a lo entendido por la parte que está firmándola. Otra opción sería asignar responsabilidades especiales hacia las partes analfabetas al conciliador para este tipo de situación.

\subsubsection{La accesibilidad}

La ley no les impone a los centros de conciliación la obligación de promover accesibilidad, especialmente a los grupos de bajos ingresos. Esta carencia puede ser contrastada con los estándares de la comisión de Georgetown que declaran: ${ }^{45}$

"Los servicios MARC deben tomar todos los pasos razonables, apropiados a su dimensión, naturaleza, y recursos, para proveer acceso a sus servicios por un costo razonable a partes de bajos ingresos».

La accesibilidad es obviamente un asunto vital, especialmente si la meta es la producción de una "cultura de paz" a través del uso de la conciliación, que es promovida como una alternativa económica al sistema formal. Si grandes sectores de la población no pueden recurrir a la conciliación a causa del costo, no se puede declarar que la conciliación es más efectiva que el sistema formal en la provisión global de justicia.

En el contexto peruano actual, la accesibilidad quizá no es un asunto tan importante como la sobre oferta de servicios conciliatorios y la correspondiente carencia de demanda. ${ }^{46}$ También se debe comprender que el

44 De preferencia, esta persona sería abogado para proveer protección máxima a la parte analfabeta.

45 CPR- "Georgetown Commission on Ethics and Standards of Practice», en: ADR. Principles for ADR Provider Organisations 2000. Paragraph IV «Access to Services». Ver página web: www.cpradr.org/cpr_george.html.

46MARC PERÚ, en: La Conciliación Extrajudicial en el Perú: Experiencia de la 
Ministerio de Justicia ha establecido «centros de conciliación gratuitos del Ministerio de Justicia” que funcionan en Arequipa y Trujillo.

No obstante, Ormachea ${ }^{47}$ nota que más de ciento sesenta centros de conciliación están ubicados en Miraflores, San Isidro y el Centro de Lima. Estos distritos no son los más poblados, sino aquellos donde hay más actividad económica. Los más poblados (y más pobres) distritos como Comas, Villa El Salvador y El Agustino tienen en promedio solo cinco centros de conciliación cada uno. Ormachea concluye que esta información demuestra que la conciliación no está contribuyendo con mejorar el acceso a la justicia: la gente que trabaja o vive en distritos pobres tiene menos acceso a centros de conciliación que los que viven o trabajan en distritos más ricos. Él sugiere, además, que no hay solamente una necesidad de más centros de conciliación en distritos más poblados, sino que también hay que asegurar que los centros actuales brinden servicios de calidad.

\subsubsection{La participación igualitaria}

El artículo $31^{\circ}$ (4) del reglamento declara que el conciliador deberá «facilitar el diálogo entre las partes, permitiendo que se expresen con libertad y se escuchen con respeto". Además, el artículo $31^{\circ}$ (7) del reglamento manda que el conciliador deberá "tratar de ubicar el interés de cada una de las partes". A su vez, el artículo $32^{\circ}$ enuncia que la ética del conciliador transita por «el desarrollo de un procedimiento de conciliación libre de presiones, con participación de las partes, y el comportamiento objetivo e íntegro del conciliador, dirigido a la obtención de un acuerdo satisfactorio a ambas». Sin embargo, no hay recomendaciones de cómo el conciliador debe comportarse para lograr estas metas. Más específicamente, no hay pautas que versen sobre cómo el conciliador debe equilibrar su obligación de ser imparcial con la obligación de asegurar que participen ambas partes.

Aplicación del Plan Piloto de Obligatoriedad en las Ciudades de Arequipa y Trujillo, Lima, MARC Perú, 2002, señala que algunos centros de conciliación en Arequipa y Trujillo cobraban solamente 5.8 US por una audiencia. Concluyó que estas acciones fueron desesperadas tentativas para atraer clientes. También notó la preocupación de varios conciliadores porque sus centros no sobrevivirán, $\mathrm{p} 23$.

47 Iván Ormachea Choque, "La conciliación extrajudicial: crónica de una muerte anunciada", en: Revista Idéele. No 146, abril-mayo, 2002, pp. 70-72. 
Idealmente, ambas partes serán igualmente capaces de expresarse y decir cuales son sus intereses y necesidades. No obstante, es posible que hayan varias ocasiones en las cuales una de las partes no sea tan capaz como la otra de expresarse. Por ejemplo, como razona NADRAC, una parte podría ser «representante profesional de una corporación, muy elocuente, con acceso a grandes recursos de dinero y asesoría" mientras que la otra podría ser «el dueño de un negocio pequeño, sin apoyo o asesoría profesional, con habilidades para su oficio pero no para expresarsem. ${ }^{48} \mathrm{En}$ este tipo de situación, ¿qué debe hacer el conciliador, si se siente el que la parte más débil está siendo dominada por la parte más fuerte? ¿Dónde se puede marcar el límite entre el auxilio a la parte y el compromiso de imparcialidad del conciliador? ¿Deben recibir las partes el mismo tratamiento por el conciliador, sean cuales fueran sus características individuales, ${ }^{49} \mathrm{o}$ debe el conciliador cambiar su comportamiento según sus percepciones sobre las habilidades de las partes?. ${ }^{50}$

\subsection{La definición de IPRECON sobre calidad}

En esta sección, exponemos la metodología empleada para construir la definición de calidad. Después, enunciamos los componentes de la definición, y luego discutimos la correspondencia con la ley y algunos de los estándares internacionales en mediación.

\subsubsection{La metodología}

Para formular una definición de calidad, entrevistamos a los tres conciliadores permanentes de IPRECON, primero individualmente, y des-

48 NADRAC, Fairness and Justice, op. cit., p. 30. Sucedió una situación similar en uno de los casos de IPRECON que consideré para las entrevistas. La cliente era la representante de una empresa grande, era elocuente, y estuvo asesorada en la conciliación por uno de los abogados de la empresa. La otra parte era una señora mayor de edad, con pocos recursos financieros, y estuvo asesorada por su hija.

49 NADRAC define este enfoque como «igualdad formal» NADRAC, Fairness and Justice, op. cit., p. 30.

50 NADRAC define este enfoque como «igualdad sustantiva». Se dice que «la igualdad del resultado requiere que los desiguales sean tratados desigualmente, que aquellos que son menos privilegiados, oprimidos, o relativamente sin poder, se les dé lo que necesiten para que puedan participar igualmente y lograr un resultado justo". NADRAC, Fairness and Justice, op. cit., p.31. 
pués nos reunimos en un taller. Las preguntas que hicimos a los conciliadores exploraron cómo explicaban ellos la conciliación a los clientes, cuáles - según ellos-eran los beneficios y riesgos de la conciliación, y qué hacían para aumentar los beneficios y reducir los riesgos. Discutimos sus percepciones acerca de lo que consideran "éxito", sus metas en la audiencia de conciliación, y cuáles eran las características de un «buen conciliador». También les pedimos sus definiciones de "justicia», y sus definiciones de "satisfacción» (de las partes y del conciliador).

A causa de los problemas que tuvimos para ponernos de acuerdo en una sola definición de justicia, ${ }^{51}$ el término fue excluido de la definición de calidad. Sin embargo, creemos que la definición expone estándares de justicia tanto como de calidad.

\subsubsection{La conciliación de calidad}

La definición de IPRECON sobre calidad es: un proceso adecuado de generar soluciones entre partes involucradas en el conflicto que sean aceptables y económicas, sin perjudicar los intereses de terceros, la comunidad y/o la sociedad en general.

\subsubsection{El proceso}

«Un proceso adecuado» en este sentido significa un proceso que satisfaga a las partes involucradas en el conflicto y al conciliador. Sin la satis-

51 La cuestión de ¿qué es justicia? es sumamente interesante en nuestra opinión, pero no puede ser tratada en el espacio disponible. Aún así, razonamos que, como en el tema de calidad, no hay una definición universal de la justicia: a lo mejor, todas las definiciones tienen como raíz concepciones basadas en ideologías. Nuestra definición personal de justicia viene de Belaief, quien manifiesta que use puede diferenciar entre una ley buena y una ley mala (o una ley justa y una ley injusta) en términos de «su tendencia a auxiliar al individuo en el más completo desarrollo de sus poderes y virtudes» o su imposibilidad de hacerlo". Rosalyn Diprose, "The gift, sexed body property, and the law", en: Pheng Cheah, David Fraser, Judith Grbich (eds), Thinking Through the Body of the Law, New York University Press, New York, 1996, p. 34. En este sentido, si un proceso de conciliación solamente reproduce, intensifica, o legitima relaciones de poder desiguales, y a través de dicho proceso se crea resultados que son encarnaciones de diferenciales de poder entre las partes, entonces el proceso y el resultado son injustos. $\mathrm{Si}$, no obstante, las partes consiguen llegar a un acuerdo que sea satisfactorio a ambas y aseguran que la proposición de justicia de Belaief se logre, entonces el proceso y el resultado serán justos. 
facción de las partes y el conciliador, el proceso no será capaz de generar soluciones aceptables". Según los conciliadores de IPRECON las partes estarán satisfechas ${ }^{52}$ cuando sientan que:

1 Han entendido el proceso y el rol del conciliador, y entonces no tengan dudas o temores del proceso;

2 El conciliador es imparcial;

3 El conciliador ha entendido los asuntos de cada parte;

4 Hay una relación de confianza entre ellas mismas y el conciliador;

5 El conciliador tiene un rol activo en la conciliación, avanzó el diálogo cuando fue necesario, e hizo sugerencias para facilitar el avance;

6 El conciliador es sensible a cualquier preocupación de las partes, y está preparado para contestar cualquier pregunta;

7 El conciliador hace todo lo posible para ayudar a las partes a resolver su conflicto;

8 Tienen la oportunidad de expresarse;

9 Son escuchados;

10 Hay una relación de respeto entre ellas mismas; y

11 No hay coacción en el proceso (de la otra parte, del conciliador, ni de terceros).

El conciliador estará satisfecho cuando:

1. Esté seguro que la participación de las partes es activa, informada, ${ }^{53}$ y consensual;

2. Las partes se respeten, aunque no lleguen a un acuerdo; $y$

3. Las partes se comporten con buena fe.

El conciliador también hará lo razonable para garantizar que las partes sean substantivamente iguales. Aunque no haya acuerdo, el conciliador estará satisfecho cuando el proceso genere entendimiento y cooperación entre las partes, se defina más exactamente los asuntos entre las partes y se propicie un método de comunicación más abierto.

Indirectamente, el conciliador espera que las partes puedan aprender, a través de su experiencia en conciliación, nuevas maneras constructivas de

52 No hay intención de que la lista sea exhaustiva.

53 Informada en el sentido que saben los beneficios de la conciliación, y las reglas del procedimiento y el rol del conciliador. 
enfrentar el conflicto. Así, las partes pueden mantener una relación positiva en el futuro, aunque no resuelvan su conflicto. En un contexto más amplio, se espera que las habilidades que aprendan las partes en la conciliación sean utilizadas en situaciones posteriores. Así habrá beneficios, para la comunidad y la sociedad (y el individuo) puesto que pueden contar con ciudadanos mejor preparados para resolver sus propios problemas. Los beneficios posibles incluyen aquellos de tipo económico (menos litigios, y entonces una reducción en los costos para el estado), los culturales (el cambio del estilo confrontacional de resolución de los conflictos a un método cooperativo, basado en el diálogo) y los sociales (reducción global del conflicto social).

\subsubsection{La solución}

"Una solución aceptable» se refiere a un acuerdo que satisfaga a las partes y al conciliador. Según los conciliadores, los indicadores importantes de satisfacción de las partes en la solución del conflicto son:

1. La solución cubre las necesidades de las partes (definidas subjetivamente);

2. Las partes no ven la solución como daño a sus intereses;

3. La solución es el producto de la voluntad de las partes, y no el resultado de la coacción de la otra parte, del conciliador, o de terceros;

4. La solución es equitativa;

5. La otra parte se siente comprometida con la solución lograda; y

6. Las partes cumplen la solución definida en el acuerdo final.

Según las entrevistas, el conciliador estará satisfecho cuando esté seguro que:

1. Las partes llegaron a un acuerdo sin coacción alguna, (de la otra parte, del conciliador o de terceros);

2. El acuerdo cubre los intereses de ambas partes;

3. La decisión de firmar el acuerdo fue informada; $y$

4. El acuerdo no contraviene la ley, ni los derechos fundamentales de las partes, ni los intereses de terceros no representados.

«Una solución económica» será realizada cuando haya:

1. Un ahorro de tiempo y dinero (en comparación con el tiempo y el 
dinero que las partes habrían gastado si hubieran participado en el sistema formal de resolución de conflictos); y

2. El evitar daño psicológico (el estrés del procedimiento formal y la ausencia de daño cualquiera causado por la conciliación.)

\subsubsection{El conciliador}

El rol del conciliador es fundamental: tiene que garantizar que haya un ambiente favorable para que las partes consigan participar igual y constructivamente en la conciliación; que el proceso y el acuerdo (si lo hay) sean satisfactorios para las partes y para sí mismo. Con el fin de lograr todo eso el conciliador tiene que:

1. Ser reflexivo (tener presente la influencia de sus creencias);

2. Tener experiencia en el proceso de conciliación;

3. Ser capaz de determinar si la conciliación es el mecanismo adecuado para el conflicto;

4. Crear una relación de confianza entre las partes mismas y también entre las partes y el conciliador;

5. Ser imparcial y neutral, al igual que aparecer imparcial y neutral;

6. Tener empatía;

7. Tener un entendimiento comprensivo de los intereses de las partes y sus concepciones del conflicto;

8. Ser capaz de generar comunicación constructiva (diálogo abierto, revelación en buena fe) entre sí mismo y las partes, y entre las partes mismas;

9. Asegurar que ambas partes puedan participar igualmente, y entonces que cualquier asimetría sea reducida o anulada;

10. Garantizar que el comportamiento de las partes sea adecuado (que las partes se comporten con buena fe y con respeto);

12 Ser capaz de avanzar el diálogo cuando sea necesario y proponer sugerencias para adelantar el proceso;

13 Ser capaz de determinar cuando la conciliación ha llegado a un punto en que se ajuste más con los intereses de las partes y deba ser concluida;

14 Guiar a las partes a una resolución satisfactoria (según las definiciones de satisfacción citadas arriba) 


\subsection{Características distintivas de la definición de IPRECON sobre calidad}

La definición de IPRECON sobre calidad tiene algunas características distintivas que destacamos en los siguientes párrafos. Notamos que la definición no depende de la creación de una solución para que se pueda decir que la conciliación fuera exitosa. El enfoque se centra en el proceso, que puede generar resultados de calidad independientemente de la solución: por ejemplo, un mejor entendimiento entre las partes. Un proceso de calidad es visto como requisito previo a una solución de calidad.

Vemos también que la satisfacción, en el proceso $y$ en la solución, es pertinente no solo a las partes, sino también al conciliador de IPRECON. Hay un presupuesto por el que el conciliador debe estar más informado sobre el proceso que las partes, y entonces, solamente la satisfacción de las partes no es suficiente. En realidad, la satisfacción del conciliador es capaz de prevalecer sobre la satisfacción de las partes: si el conciliador no está satisfecho, la conciliación podría ser terminada.

El conciliador tiene mucha responsabilidad en el proceso y el resultado y se requiere varias habilidades del conciliador para asegurar calidad. También, es parte de la tarea del conciliador crear la igualdad sustantiva, no simplemente la igualdad formal. Además, él tiene que estar satisfecho con las decisiones de las partes.

La definición, en contraste a la ley y el reglamento, considera explícitamente el amplio contexto social en que opera la conciliación, y los impactos potenciales de la conciliación sobre este. Notablemente, "los derechos fundamentales" de las partes, y los intereses y derechos de partes no representadas, son consideraciones obligatorias para el conciliador.

\section{4 .1 ¿Consistencia con la ley y el reglamento?}

Aparte del grado de responsabilidad que se pone en el conciliador de IPRECON, se puede cuestionar ¿de dónde viene la justificación del criterio de "satisfacción del conciliador", especialmente en el resultado? La ley y el reglamento hacen referencias numerosas a la voluntad libre de las partes, y a resultados que sean satisfactorios para ambas partes. En ningún momento se refiere a la satisfacción del conciliador como base o justificación de actos del conciliador. 
Además, la definición incluye preocupaciones que la ley y el reglamento no consideran en mucho detalle, o simplemente no lo hacen, como los «derechos fundamentales» de las partes y derechos de terceros. El requisito en la definición de IPRECON sobre calidad al tomar en cuenta estos derechos, da al conciliador una amplia discreción para terminar la conciliación, y así efectivamente anular la posibilidad de un acuerdo. Este es expresado en lenguaje considerablemente más enfático que los códigos o las pautas discutidos arriba, y también que la ley y el reglamento, que requieren, al máximo, que ciertos intereses sean tomadas en cuenta. Crucialmente, el conciliador se ubica como una especie de «árbitro final» de los acuerdos, lo cual es discutible teniendo como marco la ley o el reglamento.

\subsubsection{Consentimiento informado}

Uno de los conciliadores dijo que en el caso que las partes no estuvieran informadas de sus "derechos fundamentales», él se los informaría. Varios asuntos surgen en este contexto. El primero es ¿qué son los derechos fundamentales? El segundo es ¿quién tiene el derecho de definirlos? El tercero es ¿cómo podría comprometer la imparcialidad del conciliador la provisión de tal información, especialmente si una de las partes pudiera ver tal acción como una asociada a un prejuicio político?. ${ }^{54}$

Por otro lado, uno de los conciliadores dijo que nunca ofrecería información sustantiva sobre las complicaciones legales de un acuerdo, sino referiría a las partes a un asesor profesional. Si ellas lo rechazaran, él consideraría la terminación de la conciliación, dependiendo de las circunstancias. Entonces, se puede ver dos maneras distintas de tratar la misma situación entre los conciliadores.

Los conciliadores también dijeron que nunca discuten los riesgos potenciales o las desventajas de la conciliación con los clientes, puesto que

54 Esta declaración no propone que es posible que el conciliador ocupe una posición "fuera" de la política. En efecto, la noción de imparcialidad es muy complicada, a través del campo de los MARC. Una discusión sobre la imparcialidad no es posible aquí, pero creo que es importante enfatizar lo que dijo uno de los conciliadores IPRECON: «Aunque sea un mito que un conciliador pueda ser totalmente imparcial, los conciliadores tienen que esforzarse por aparecer imparcial. Si uno de las partes interpreta las acciones del conciliador como favoritismo a un prejuicio político, este podría afectar la relación de confianza entre esa parte y el conciliador». 
eso podría causar el retiro de la conciliación de una o ambas partes. Sin embargo, ¿será que tal revelación sea necesaria para cumplir con el requisito de consentimiento informado?

El artículo $31^{\circ}$ (3) del reglamento norma que el conciliador informará a las partes sobre «el procedimiento conciliatorio, su naturaleza, características, fines y ventajas". No hay nada explícito, por lo tanto, de un requisito a informar a las partes sobre los riesgos posibles o desventajas. Tal enfoque, de IPRECON y del reglamento puede ser contrastado con los estándares de práctica de familia que declaran que: ${ }^{55}$

"Cuando la mediación es apropiada: El mediador auxiliará a las participantes para que evalúen los beneficios, riesgos y costos de la mediación y otras alternativas disponibles a ellas".

\subsubsection{La conciliación: ¿mecanismo para cambio social?}

Si evaluamos la definición en términos de las seis categorías de BaruchBush, podemos ver que mientras quiere brindar satisfacción individual, autonomía individual, y transformación personal, IPRECON también está preocupado por la justicia social. No es claro que estos requisitos puedan existir juntos, por lo menos igualmente. Por ejemplo, el derecho del conciliador a terminar la conciliación basada en preocupaciones sobre justicia social, como la necesidad de asegurar que la resolución no sea dañosa a los intereses de terceros, entra fundamentalmente en conflicto con la satisfacción de las partes y su autonomía, especialmente con el control de la solución al conflicto.

Estos asuntos tienen que ver con una discusión hecha por Luban y también NADRAC. Luban dice: ${ }^{56}$

« [...] demasiadas tentativas del tercero para potenciar (a la parte más débil) terminarán con la subutilización de los MARC por las partes más poderosas [...]. Por lo tanto, los MARC como organización política $^{57}$ son una maquina que no funcionará debido a esta visión».

55 Los estándares de práctica de familia, op. cit., párrafo $2^{\circ}$.

56 David Luban, "The Quality of Justice», en: Denver University Law Review, Vol. 66,1989 , p. 413.

57 «La organización política» en este sentido se refiere a un prejuicio político: por ejemplo, el favorecer a la parte más débil en la conciliación. 
De un ángulo político distinto, NADRAC propone que:

"Un problema significativo con la igualdad sustantiva es, salvo que los poderosos reconozcan que la creación de un "campo plano" (en la conciliación) requiere que la otra parte necesite recibir más ayuda, van a protestar que lo que sucede no es justo, no es igualitario [...]. Pueden sentirse que merecen hacer uso de su ventaja y no quieran renunciar a ella a favor de la igualdad real [...]. Es también posible que simplemente no vean la injusticia porque ven su privilegio como algo normalm. ${ }^{58}$

Los asuntos planteados por NADRAC y Luban necesitan reflexión profunda. ¿Cuáles son los objetivos de la conciliación, y hasta cuándo pueden dominar los objetivos de justicia social las consideraciones de satisfacción individual, o viceversa? El favoritismo de un enfoque, por ejemplo el de justicia social, puede hacer que las partes más poderosas vean la conciliación como una opción menos atractiva. Sin embargo, otorgar prioridad a la satisfacción individual puede causar el abuso de derecho contra las partes menos poderosas. No será nada simple encontrar un equilibrio, pero estas consideraciones son cruciales en la determinación de qué "cultura de paz" pueden crear la ley y el reglamento.

\section{Entrevistas a los clientes}

En esta sección discutimos el objetivo y la metodología utilizada en las entrevistas con varios clientes anteriores de IPRECON. También planteamos asuntos que se relacionan a la satisfacción de las partes como una medida de calidad y la utilidad de medidas de tiempo y costo. Después, presentamos algunos resultados sobre la práctica de IPRECON, basados en las entrevistas y la definición de calidad de IPRECON.

\subsection{El objetivo y la metodología de las entrevistas}

El objetivo de las entrevistas era ganar un entendimiento de las perspectivas que tienen los clientes de IPRECON de su servicio conciliatorio, 
y comparar esas perspectivas con la definición de calidad de IPRECON y los estándares internacionales de mediación. Aunque solo hicimos seis entrevistas, todavía creemos que las respuestas de estas entrevistas valen la pena ser consideradas, ya que nos dan algunas interesantes y valiosas revelaciones en las percepciones de aquellas personas que tuvieron un contacto con la conciliación por "primera vez", o en uno de los casos por «segunda vez".

\subsubsection{Problemas encontrados}

Fue muy difícil encontrar gente que estuviera dispuesta a acceder a una entrevista. El criterio de selección de candidatos que teníamos rápidamente falló, como muchas de las personas con quienes queríamos comunicarnos habían cambiado de dirección, o no tenían teléfono. Otras personas rehuyeron una entrevista inmediatamente, o después nos dijeron que estaban demasiado ocupadas. Otras expresaron voluntad de colaborar, pero después no fue posible contactarlas para fijar una entrevista. Era sumamente difícil comunicarse con gente que no trabajaba en una empresa o una entidad del gobierno, pues muchas solían regresar muy tarde a sus casas. Esperábamos entrevistar entre doce a quince personas, e hicimos alrededor de cuarenta solicitudes para entrevistas. Lamentablemente, solo seis de los clientes que contactamos colaboraron con el estudio.

Esta experiencia demuestra que se necesita tener documentación detallada (tales como números telefónicos, dirección particular y laboral) de clientes anteriores, si se quiere conducir proyectos como este en el futuro. Sin embargo, la información detallada será ineficaz cuando la gente cambie de dirección o no tenga teléfonos. Tal vez sea más fácil conducir encuestas que entrevistas cualitativas, pero la información que se obtenga de las encuestas será distinta a la información que podrían brindar las entrevistas cualitativas.

Otra consideración importante es el tiempo. Si hubiéramos sabido más temprano de los problemas que encontraríamos, hubiéramos comenzado la búsqueda de clientes mucho antes de lo que se hizo. Las tres semanas que dedicamos a esta tarea no fueron suficientes.

\subsubsection{Metodologia}

Dos de las entrevistas fueron realizadas por teléfono, según los deseos del cliente. Las otras fueron realizadas "cara a cara", con un programa de 
preguntas. Ninguna de las entrevistas fue grabada: solamente tomábamos notas detalladas mientras hablaba el cliente. Todos los clientes, menos uno, no había tenido una anterior experiencia con la conciliación. El caso de la excepción había tenido otra experiencia, también con IPRECON, antes del caso que discutimos con ella.

Entrevistamos a cinco mujeres y un hombre. Todos eran profesionales, $y$ todos fueron asesorados por abogados durante las audiencias. ${ }^{59}$ Todas las audiencias habían tenido lugar dentro del último año. El rango de sesiones conciliatorias en cada audiencia osciló entre una a veinte reuniones. Los conflictos administrados trataban sobre disputas sobre arrendamiento de una inmueble, régimen de visitas/acuerdo de divorcio, deuda y participación en el mercado, los limites de varios terrenos, una garantía, y un acuerdo de cese de empleo. En el caso del acuerdo de cese de empleo, no había una disputa entre las partes, sino querían usar el acta de conciliación como formalización de un acuerdo entre las partes. Ambas concordaban sobre la naturaleza del acta antes de asistir a la audiencia de conciliación.

Las preguntas que hicimos a los clientes estuvieron concentradas en el proceso, la resolución, y el trabajo del conciliador. Las preguntas sobre el proceso buscaban el desarrollo de un entendimiento sobre las percepciones de los clientes antes de que asistieran a la audiencia, cuáles fueron sus preocupaciones y si estas preocupaciones fueron satisfechas. Después tratábamos de generar una discusión sobre cómo les explicó el conciliador la conciliación, quién estaba presente en la audiencia, cómo se sentían de su participación en la audiencia y su valor, y cómo afectó la audiencia el conciliador. También les preguntábamos si pensaban que habían aprendido nuevas destrezas durante el proceso.

Las preguntas sobre la solución definitiva fueron dirigidas a la exploración de cómo llegaron a la solución, o, si no había solución, como fue concluida la audiencia. También les preguntábamos sobre su satisfacción en la solución final, si había terminado la disputa en cuestión, y si recibieron asesoría profesional antes de firmar el acuerdo final. Finalmente, les preguntamos si escogerían al IPRECON de necesitar servicios conciliatorios otra vez.

59 Noremos que el artículo $10^{\circ}$ de la ley declara que «la audiencia de conciliación es única y comprende la sesión o sesiones necesarias para el cumplimiento de los fines previstos en la presente ley". 


\subsection{Problemas con «la satisfacción de las partes» como una medida de calidad}

Un criterio muy claro, directamente relacionado a este asunto, es el de NADRAC que señala: «la carencia de conciencia pública y profesional (por sobre lo que se espera de los MARC) significa que los datos obtenidos de las partes y las entidades que derivan casos tal vez no sean una medida de servicio totalmente válida y confiable». ${ }^{60}$ Además, como muchos individuos pueden usar MARC como servicios una vez y no más, tal vez no tengan ellos punto de comparación.

Luban desarrolla este punto general con el planteamiento de los siguientes cuatro problemas con la idea de lograr la satisfacción de las partes. $^{61}$

a) Externalidades: Las decisiones de las partes suelen tener efectos que van más allá de la relación entre ellas, y pueden afectar los derechos o intereses de terceros. Luban nos da el ejemplo de un acuerdo entre un hospital y un grupo de residentes, sobre un plan de construir una casa de retiro en el barrio de los residentes. La solución conciliada es que el hospital la construirá en otro barrio más pobre, donde hay menos probabilidad que sus residentes reclamen. Por lo tanto, aunque las partes que asisten a un proceso MARC estén satisfechas con el resultado, una externalidad negativa ha sido puesto en «una parte no involucrada (en el proceso) y que a su vez no está representada». ${ }^{62}$

b) «Enfriamienton: El eje de este problema es explicado por Luban para decir que: «Los participantes no están satisfechos necesariamente porque el proceso haya sido bueno, sino porque sus expectativas han sido ilegítimamente reducidas", ${ }^{63}$ por el tercero, sus abogados u otros terceros. Así, un proceso que no cumpla con otros criterios importantes de calidad, como el consentimiento informado, puede producir clientes «satisfechos» que no sabían que, en realidad, la solución representa una pérdida significante para ellos.

60 NADRAC. A Framework for ADR Standards. ("Framework for ADR Standards") Párrafo $2^{\circ} .79$. Ver página web www.law.gov.au/aghome/advisory/nadracl frameworkfiles. htm.

61 Luban, op. cit., pp. 413-409.

62 Ibid, p. 404.

63 Ibid, p. 405. 
c) Insensibilidad de distribución: este principio significa que el hecho que una parte se sienta muy contenta con el resultado no significa, necesariamente, que la satisfacción de ambas partes haya sido lograda. En efecto, se puede sospechar que si una parte se encuentra muy satisfecha con el resultado, la otra puede estar muy insatisfecha con ello, o no sabía que estaba aceptando menos de lo que debía haber aceptado.

D) Falta de Información: este principio se refiere a la preocupación que, especialmente aquellas partes sin experiencia, puedan estar muy satisfechas con la conciliación. Eso puede deberse a que el conciliador hizo una tarea buena. No obstante, como razona Luban, este sentimiento de las partes podía haber sido por falta de experiencia, mientras que un observador con experiencia habría visto el comportamiento del conciliador como manipulador o parcializado.

Con esta discusión sobre los problemas relacionados a la satisfacción de las partes según Luban, uno puede preguntarse ¿para qué entonces hacer las entrevistas de la presente investigación? Primero, un punto fundamental es que estos problemas no desvalorizan totalmente los resultados de una entrevista sobre satisfacción. Mejor dicho, significa que las conclusiones tienen que ser provisionales, y la satisfacción de las partes con un servicio no significa, necesariamente, que los proveedores de tal servicio puedan pretender que este es de "calidad". Segundo, rechazar la satisfacción de las partes totalmente como indicador de calidad sería no valorizar suficiente la habilidad de los clientes para diferenciar entre distintos niveles de servicio. Sería arrogante asumir que los clientes son incapaces de hacer evaluaciones sin la asistencia de profesionales.

Por lo tanto, los resultados tienen que ser evaluados cuidadosamente, pensando en las advertencias de Luban y otros. No obstante, eso está lejos de significar que no tienen valor. Tampoco impide que el objetivo de las entrevistas (arriba citado), sea logrado. Además, la definición de IPRECON sobre calidad se relaciona con algunos de estos problemas, en tanto declara la satisfacción del conciliador como un componente de calidad, tanto como la satisfacción de las partes.

\subsection{La utilidad de comparaciones de tiempo y costo}

La ley y la definición de IPRECON sobre calidad se refieren a ahorros de tiempo y dinero en comparación con el sistema formal. No obstante, 
estos ahorros serán realizados solo cuando haya acuerdo. Si no lo hay, el cliente habrá incurrido en los costos de la conciliación, y también tendrá que someterse a un proceso formal. $\mathrm{Y}$, aunque haya acuerdo, si la otra parte no lo cumple, el cliente tendrá que enfrentar más gastos para hacer que la otra parte cumpla con lo acordado.

Las estadísticas de IPRECON indican que una proporción considerable de los casos donde asisten las partes no terminan en acuerdo total. Por ejemplo, entre julio y diciembre de 2001 , de veintinueve casos donde asistieron ambas partes, once fueron concluidos a causa de la falta de acuerdo entre las partes. Por lo tanto, las partes que no llegaron a un acuerdo tendrían que dejar el conflicto no resuel to, hacer otros esfuerzos para resolver el conflicto entre sí mismos o recurrir a un proceso formal.

Además, el hecho que las partes consiguieran un acuerdo total no significa necesariamente que el conflicto entre ellas terminó para siempre. Lamentablemente, no hay estadísticas disponibles sobre el cumplimiento de los acuerdos. Aun así, dos de los clientes que entrevistamos, quienes supuestamente habían llegado a acuerdo total, habían tenido otros problemas. En uno de los casos, la otra parte no cumplió con el acuerdo, y en el otro, una cláusula ambigua significó que una faceta del conflicto original entre las partes involucradas se quedase sin resolución.

También, las estadísticas muestran que muchas conciliaciones son concluidas por inasistencia de una o ambas partes. Por ejemplo, entre julio y diciembre de 2001, IPRECON recibió cincuenta y ocho solicitudes. Sin embargo, de estas cincuenta y ocho, veintiséis fueron concluidas por inasistencia de una o ambas partes. Para éstas, por lo tanto, la obligación de solicitar la conciliación de acuerdo a lo prescrito por el artículo $9^{\circ} \mathrm{de} \mathrm{la}$ ley, les resulta un gasto mayor de tiempo y dinero que no habrían realizado si el caso hubiera ido directamente a un proceso judicial. ${ }^{64}$

Finalmente, hacer comparaciones entre una resolución conciliatoria y una hipotética resolución judicial es siempre difícil. Astor y Chinkin declaran que, en Australia, más del $90 \%$ de las disputas no llegan a un proceso formal. ${ }^{65}$ Entonces no se puede comparar, sin mayores elemen-

64 No obstante, notemos que la investigación de MARC-Perú explica que muchos de los secretarios y directores de centros de conciliación entrevistados tenían la opinión que mucha inasistencia se debió a causa de la asesoría que recibieron las partes de sus abogados. MARC-Perú op. cit., p. 6. Los conciliadores de IPRECON también expresaron las mismas conclusiones.

65 Hilary Astor y Christine Chinkin, «Litigation and Alternative Methods Compared», 
tos, los gastos de resoluciones conciliatorias con los de los procesos formales. Por ejemplo, las partes de una disputa podrían arreglarla entre ellas antes de comenzar un proceso formal, lo que significaría que sus gastos serían menores que el promedio, si se hicieran los procesos formales, $y$ tal vez menos que los de los procesos conciliatorios.

\section{4. ¿¿Servicio de «calidad»?}

La información obtenida de las entrevistas no es suficiente para discutir todos los elementos de esta definición. Sin embargo, creemos que las respuestas sí nos dan información suficiente para plantear varias observaciones. Éstas se relacionan con la satisfacción de las partes en el proceso, la solución, y el conciliador, si los clientes pensaron que habían aprendido destrezas nuevas durante el proceso, el asunto del consentimiento informado, si las resoluciones fueron económicas, y la importancia de la participación de abogados en el proceso conciliatorio.

\subsubsection{Proceso}

Todos los clientes estuvieron satisfechos con el proceso. Especialmente, los entrevistados sin excepción pensaban que tuvieron la oportunidad para expresarse, y ser escuchados. En el caso de la disputa sobre los terrenos, la cliente enfatizó cómo había sido valiosa la conciliación en la provisión del espacio en lo que las otras partes podrían hablar y "contar todas sus historias, porque antes (de la conciliación) todos los campesinos rechazaban hablar con nosotros y entre sí mismos sobre estos asuntos".

En el caso sobre garantías, la cliente insistió que la conciliación ayudó mucho para cambiar «el clima» de las reuniones entre las partes. La provisión del espacio neutral en cual las partes podían hablar sobre los asuntos fue crucial, puesto que las reuniones anteriores en la oficina de la cliente dejaron que la otra parte se sintiera amenazada. El traslado de la discusión al espacio neutral tenía, según la cliente, un efecto marcado en el humor de la otra parte (ella se quedó menos agresiva y menos preocupada) y también en su voluntad para negociar.

en: Hilary Astor y Christine Chinkin, Dispute Resolution in Australia, Sydney, Butterworths, 1992, p. 16. 
Los clientes contaban que antes del comienzo de la audiencia, el conciliador hacía una presentación corta para informarles sobre la conciliación. Todos dijeron que el conciliador se enfocó en los posibles beneficios de la conciliación, como método rápido y barato de solución y una oportunidad de evitar un proceso formal. Se enfatizó también que el acta tenía el valor de un título de ejecución. Todos los clientes comentaron que después de la presentación del conciliador, se sintieron informados sobre el proceso y que habían entendido todo lo necesario para poder participar en la audiencia. Todos dijeron que se sintieron cómodos con el conciliador.

\subsubsection{La Solución}

Tres de los clientes declararon inequívocamente que las soluciones de sus conflictos cubrieron todas sus necesidades. Todos los clientes consideraban las soluciones como algo que ellos produjeron, sin coacción. Sin embargo, en por lo menos tres de los casos hubo alto nivel de participación de abogados.

El caso de arrendamiento de un inmueble fue lo único en que la solución conseguida fue totalmente incumplida. La cliente en este caso estaba originalmente muy satisfecha con la solución puesto que pensaba que reflejó un resultado apropiado: que la otra parte (la inquilina) pague sus deudas y desaloje la casa. No obstante, la inquilina últimamente rehuyó sus obligaciones según señala el acuerdo. En este caso, un proceso formal no fue necesario, puesto que eventualmente se llamó a la policía para desalojar a la inquilina. La deuda de la inquilina no fue recuperada.

Cuando preguntamos a la cliente si pensaba que el conciliador había sido imparcial, ella dijo que sí, pero también que a veces pensaba que el conciliador se parcializó a su favor, y que él "presionaba a la otra parte, sugiriéndole soluciones de cómo podría pagar su deuda». La cliente pensó que eso fue importante, como la otra parte siempre le había dicho a la cliente que no tenía cómo pagar la deuda, pero en la audiencia el conciliador «no la dejaba responder así e hizo que ella recordara que tenía su pensión".

En este caso, la otra parte (no entrevistada) podría haber visto la solución como una afectación a sus intereses, pero aun así la aceptó, tal vez por el deseo de terminar la audiencia. La otra parte no estaba asesorada, mientras que la cliente estuvo asesorada por su abogado. Es discutible que la otra parte se podría haber sentido bajo presión del conciliador y la 
cliente, y aceptó la solución solamente para concluir la audiencia, aunque no tenía una intención verdadera de cumplir con sus obligaciones en el acta. Estas conclusiones se convierten más probables cuando se considera que la cliente misma dijo que la otra parte protestó posteriormente que "sabía que el acta era vinculante, pero solo decía otra vez que no tenía la plata para pagar la deuda».

Es posible que la insensibilidad de distribución se realizara en este caso: mientras que la cliente estuvo muy satisfecha con la solución, es obvio que la otra parte no lo estaba, y eso afectó la durabilidad de la solución final.

En el caso de una deuda y participación en el mercado, se concilió el primer asunto. No obstante, el conflicto continúa sobre el segundo asunto puesto que una disputa ha surgido sobre el significado de la cláusula en el acta que se redactó para resolver el conflicto. Además, el cliente involucrado en el caso dijo que aunque no estaba satisfecho con la solución en conjunto (porque pensó que la suma negociada de la deuda era menos que la que la otra parte le debía, y porque pensó que la cláusula sobre la participación en el mercado era ambigua) la aceptó por «necesidad económica». Por lo tanto, es discutible que él fuera coaccionado para lograr una solución no satisfactoria, desde su punto de vista, por su posición económicamente débil (en relación a la otra parte).

En los otros tres casos en los cuales se logró una solución, ésta ha sido duradera. Una cliente enunció que estaba muy satisfecha con la solución puesto que así se evitó «un largo y costoso proceso formal». Otra cliente agregó que la solución era muy satisfactoria porque «tal vez hubiéramos ganado un proceso formal, pero mis experiencias anteriores del sistema formal me indicaron que un proceso formal habría demorado años". Otra dijo que estaba "muy contenta» con la solución que puso fin a un conflicto de tres años de duración en poco más que dos horas. La solución en este caso, el de la garantía, significó que no era necesario un proceso formal. Si dicho proceso hubiera sido necesario, la cliente (su evaluación fue basada en su experiencia pasada y actual del sistema formal) pensó que el conflicto podría haber continuado por aun más años.

No llegaron a una solución en el caso del régimen de visitas. Después de casi tres meses de audiencia, el conciliador propuso que concluyera la conciliación, puesto que no pensaba que las partes iban a conciliarse. La otra parte estaba de acuerdo, y la audiencia fue concluida, a pesar de que la cliente quería continuar la conciliación. Hasta ahora el conflicto está sin solución. 


\subsubsection{El conciliador}

Todos los clientes se profesaban satisfechos con el trabajo del conciliador. Todos concluyeron que el conciliador que manejó su caso se comportaba de una manera profesional y respetuosa, y se forzaba mucho para auxiliar a las partes a llegar a una solución. Todos declararon que confiaban en el conciliador y creían que condujo imparcialmente la audiencia.

Especialmente, dos clientes comentaban sobre el manejo del conciliador en la interacción entre las partes. Ambas dijeron que uno de los factores que dejaban sentirse capaces de contar su versión de los hechos, fue que el conciliador dio a cada parte la misma cantidad de tiempo para hablar. Dos clientes afirmaron que antes de que ocurriera la conciliación, el diálogo entre las partes había terminado completamente o nunca había existido. Durante la audiencia, el conciliador alcanzó el re-establecimiento del diálogo entre ellas.

Una cliente enfatizó la decisión del conciliador de reunirse por separado con las partes durante una crisis como una acción que rescató la conciliación. Todos opinaban que las sugerencias que hacía el conciliador como soluciones posibles o maneras de seguir adelante fueron útiles. También pensaron que el conciliador estaba bien informado sobre su caso y entendía los asuntos de cada parte. Ninguno tenía comentario negativo sobre el trabajo del conciliador, salvo la preocupación (discutida a continuación) que el conciliador en uno de los casos no declaró en el comienzo que no era abogado.

Si bien es cierto que ninguno de los clientes escogió IPRECON (sus abogados lo hicieron), todos dijeron que, si necesitaran la conciliación otra vez, recurrían nuevamente a IPRECON. Cuando les preguntamos porqué, los clientes puntualizaron la habilidad del conciliador como un factor crucial. Aparte de eso, una de las partes dijo que IPRECON parecía "confiable". Todos mencionaron los aspectos físicos de las oficinas de IPRECON y su ubicación, como razones para ser recomendada IPRECON o por pensar que era una organización «respetuosa» o «buena». En particular, los clientes comentaban favorablemente sobre la presentación de las oficinas, su ubicación en un distrito de clase media alta, la presencia de la secretaria, y las actitudes "serias y respetuosas" de los conciliadores. 


\subsection{4 ¿Nuevas destrezas?}

Cuatro de las partes reflexionaban que habían aprendido destrezas nuevas durante el proceso. Una razonó que sintió que el proceso le ayudó a aprender a comunicarse mejor con la otra parte. Otro pensó que había aprendido mejores maneras de negociar, y otra tenía la impresión de haber conseguido una forma menos confrontacional de tratar los conflictos. Otra, «cómo ceder un poco para llegar a la solución sin perder».

Sin embargo, es difícil evaluar, dada la pequeña cantidad de entrevistas y la información ganada de ellas, si los clientes aprendieron destrezas en las audiencias que podrían utilizar o utilizarían independientemente del conciliador para manejar los conflictos. Una cliente expresó directamente que aunque sintió que la conciliación fue vital en el re-establecimiento del diálogo entre ella y la otra parte, ella sola no habría sido ni sería en el futuro capaz de crear el diálogo: la asistencia y habilidad del conciliador fueron críticas en la producción de este diálogo. En fin, parecía que la experiencia de la conciliación significó que los clientes estarían más dispuestos, y mejor preparados, para participar en una conciliación en el futuro. No significó, no obstante, que el cliente necesariamente se sienta más capaz de tratar sobre conflictos sin el auxilio de un conciliador ( $\mathrm{y}$ tal vez abogados también).

A pesar de eso, es razonable que si estos clientes se sienten más cómodos que antes con la conciliación, existe el potencial para obtener ganancias sociales, en términos de reducir el litigio y también más utilización de un mecanismo no confrontacional de resolución de conflictos.

\subsubsection{Consentimiento informado}

Todos los clientes casi nada sabían sobre conciliación antes de asistir a la audiencia por primera vez. Todos dependían de información de sus abogados hasta la audiencia. Parece que los abogados les dieron a los clientes información relativamente limitada sobre cómo sería la audiencia. Las explicaciones oscilan entre aquellos que dicen que la conciliación es un proceso que las partes podrían utilizar para llegar a una solución sin tener que irse al sistema formal y aquellos que firman que es un proceso que ayudaría al establecimiento de diálogo entre las partes. Los clientes, aparentemente, no tenían mucha idea de cuál sería su rol o el del conciliador en la audiencia. 
Además, mientras que en todos los casos los clientes fueron asesorados por abogados, tres de las partes invitadas a conciliar no fueron asesoradas en la audiencia de conciliación, mientras que una de las partes en oposición solo fue representado por algunas de las sesiones de la audiencia. Por lo tanto, es probable que por lo menos tres de las partes invitadas sabían muy poco sobre la conciliación antes de asistir a la audiencia, y eran completamente dependientes del conciliador para ser informados.

No fue claro (porque los clientes no recordaban con muchos detalles) como fue la explicación del rol del conciliador y de las partes. Ninguno de los clientes se acordó que el conciliador discutía posibles riesgos, y tampoco eran conscientes que podría haber riesgos en el proceso. Solamente uno de los clientes dijo que sabía que podía terminar la conciliación cuando quisiera, pero eso fue a causa de la asesoría de su abogado. En un caso, nuestra pregunta sobre el conocimiento de riesgos posibles provocó una reacción de sorpresa de la cliente. Después de preguntarnos sobre cuáles podrían ser los riesgos, se molestó que estos asuntos no fueran discutidos con ella.

\subsection{6 ¿Soluciones económicas?}

En el caso del régimen de visitas, sería difícil proponer que el proceso resultó en ahorros de tiempo o dinero para las partes involucradas. Mientras que, discutiblemente, habrían gastado más recursos en un proceso formal, este les habría conferido una solución. La conciliación, sin embargo, no les brindó una solución definitiva, y más bien implicó un gasto considerable de tiempo, dinero y energía. Lamentablemente, el proceso tampoco les ayudó a acercarse a una solución independiente, puesto que ninguno de los asuntos en conflicto han sido resuelto posteriormente a la conciliación.

Es posible, en el caso del arrendamiento de un inmueble, que el acta conteniendo el acuerdo haya ayudado al cliente a conseguir el apoyo de la policía en el desalojo de la inquilina. A pesar de eso, la solución alcanzada por las partes no fue cumplida, y finalmente la cliente nunca recuperó la deuda de la inquilina. Si la policía no hubiera intervenido, la cliente habría tenido que recurrir al sistema formal, y entonces habría incurrido en todos los gastos que dicho proceso habría acarreado.

En el caso del acuerdo de cese de empleo, la solución, en las palabras de la cliente «evitó un largo y extenso proceso judicial». En este caso, «una 
solución económica» fue alcanzada, pero como las partes ya estaban de acuerdo antes de asistir la audiencia, es difícil atribuir la solución al proceso conciliatorio o a las habilidades del conciliador.

En el caso de la deuda y la participación en el mercado, el cliente tenía la opinión que aunque el segundo asunto se quedó sin resolver, la audiencia significó que un proceso formal, al menos hasta el día de la entrevista, no había sido necesario. Consideró que un proceso formal habría producido "mucho odio y muchas luchas entre las partes, puesto que eso es lo que sucede (en el sistema formal)». Eso significó que, a pesar de que el proceso conciliatorio no fuera totalmente exitoso, el cliente no estaba seguro que un proceso formal hubiera producido un resultado «mejor".

En el caso de los terrenos, la cliente precisó que las resoluciones realizadas en la conciliación habían ahorrado "mucho dinero, tiempo, y estrés", y que la conciliación había sido muy efectiva en la solución de asuntos complicados y la creación de una solución duradera. Esa experiencia la incentivó a utilizar la conciliación otra vez en otra disputa sobre una propiedad alquilada. En este caso, la conciliación también produjo una solución duradera, que fue lograda, en la opinión de la cliente, mucho más rápidamente y a un costo menor que en un proceso formal.

En el caso de la garantía, como mencionamos arriba, una audiencia de un poco más de dos horas alcanzó lo que tres años de esfuerzos independientes de las partes no fueron capaces de lograr: una solución duradera. La cliente dijo que el sistema formal en Lima estaba "saturado e era incapaz de procesar los casos pendientes». Ella consideró que la conciliación podría ofrecer una gran oportunidad de aliviar parte de la pesada carga del sistema formal, y calificó la conciliación de "capaz de producir soluciones rápidamente». Desde el punto de vista de la empresa, la solución rápida fue vital. Debido a ésta, se podía explotar una oportunidad comercial que, sin la resolución del conflicto, se hubiera perdido. En este caso, una opción era desalojar a la otra parte, pero eso habría costado tiempo y dinero, y habría dejado a la otra parte sin nada. En vez de eso, la conciliación permitió que las partes llegaran a una solución que cubrió los intereses de ambas. La otra parte estuvo tan satisfecha con la solución que le envió una carta de agradecimiento a la cliente.

Por lo tanto, una solución económica fue alcanzada en cuatro de los casos, ${ }^{66} \mathrm{si}$ aceptamos que en éstos habría costado más un proceso formal

66 Se puede aumentar este total a cinco, si se contara el caso del alquiler de la propie- 
en términos de tiempo, dinero, y gasto psicólogo. Sin embargo, se debe notar otra vez que en el acuerdo de cese de empleo, no había conflicto.

\subsubsection{La participación de abogados}

Es interesante notar el significativo nivel de influencia y participación que tenían los abogados en todas las audiencias. Como ya fue dicho, todos los clientes fueron asesorados por abogados. Una cliente consideró que se sentía más cómoda con la presencia de su abogado, quien podía asesorarla cuando ella lo necesitaba. Otro dijo que vino primero solo, pero cuando vio que la otra parte tenía su abogado, él consiguió uno "para seguridad",en todas las otras sesiones de la audiencia.

También es relevante señalar que una cliente precisó que mientras que confiaba en el conciliador, estaba preocupada al descubrir que no era abogado, y que él lo debía haber declarado en el comienzo. Opinó que se habría sentido más segura con un abogado-conciliador, puesto que «un abogado estaría más informado sobre asuntos legales que surjan».

Es difícil hacer conclusiones sólidas con la información disponible sobre cómo los abogados hubieran afectado el proceso. Mientras que todos los clientes no consideraban que sus abogados habían dominado el proceso o les habían impedido participar libremente, la cliente en el caso de los terrenos dijo que "fueron los abogados quienes más hablaban". También consideró ella que "la conciliación sería un desperdicio de tiempo sin los abogados puesto que ellos saben negociar y seguir adelante».

Creo que es factible decir que la conciliación en el Perú todavía opera mucho "en la sombra de la leym. ${ }^{67}$ No es solamente establecida por una ley, sino la legitimidad de los conciliadores puede depender, según algunos, de la proximidad que ellos tengan al sistema formal, precisamente a lo cual la conciliación es supuestamente una alternativa. Los clientes también unánimemente valorizaron la participación de los abogados en las audiencias, mientras que había diferencias en el grado de valorización. Lo que es interesante notar es que en el caso de la deuda y participación en el mercado, la participación de abogados resultó en un acta que ha creado

dad, en el cual estaba involucrada la cliente del caso de los terrenos. Por otro lado, no es seguro que el acta de la disputa sobre una deuda y participación en el mercado produjera una solución económica, puesto que continúa el conflicto sobre el segundo asunto.

67 Marc Galanter, "Justice in Many Rooms" en: M. Cappelletti, Access and Justice and the Welfare State, New York, Sijhoff, 1981. 
otros problemas, debido a la sumamente pobre redacción de la cláusula sobre participación en el mercado.

\section{Conclusiones}

\section{1. ¿IPRECON: centro de calidad?}

Aunque, en este conocimiento, todas las conclusiones tienen que ser provisionales, el análisis de las respuestas de los clientes muestra que muchos de los criterios de calidad de IPRECON fueron alcanzados en los casos considerados.

Todos los clientes expresaron altos niveles de satisfacción con el proceso conciliatorio y el conciliador. Varios clientes comentaron sobre la manera exitosa que el conciliador propició el diálogo entre las partes, la confianza que tenían en él y la importancia de la provisión de un espacio neutral y cómodo en que las partes podían tratar de resolver su conflicto. Cuatro de los clientes pensaron que aprendieron nuevas destrezas en el manejo de los conflictos a través del proceso conciliatorio.

El caso de arrendamiento de un inmueble planteó algunas áreas de preocupación en el proceso, pero sin más información es imposible decir definitivamente cuáles fueron las razones que llevaron al incumplimiento del acuerdo. La discusión del consentimiento informado demuestra que se puede informar más a los clientes.

En la mitad de los casos, se logró una solución que, según al cliente, cubrió todas sus necesidades. El hecho que no se haya logrado una solución en el caso del régimen de visitas no disminuye las percepciones de la cliente sobre la calidad del proceso en este caso. Se puede atribuir los asuntos pendientes en el caso de la deuda y participación en el mercado más a las partes y a sus abogados que al proceso conciliatorio de IPRECON. Además, en este caso la conciliación sí logró una resolución durable en el asunto de la deuda. Las resoluciones en los casos del acuerdo de cese de empleo y los terrenos han sido duraderas, y la cliente en el segundo caso también utilizó otra vez los servicios de IPRECON para alcanzar una solución de largo plazo.

El éxito de IPRECON en la tan rápida resolución del caso de la garantía (que tenía mucho tiempo de vigencia) tiene que ser especialmente destacado. Aunque antes de participar en una audiencia la cliente tenía 
poca fe en la habilidad de la conciliación para lograr resultados, consideró en la entrevista que ahora la percibe como una institución potencialmente muy útil para su empresa. Eso fue, según ella, a causa de la celeridad, calidad (en términos del cubrimiento de los intereses de ambas partes) y economía (en términos de ahorro de tiempo, dinero y estrés) de las soluciones que podría generar la conciliación.

No se pueden hacer, en la ausencia de una evaluación cuantitativa, conclusiones determinadas sobre la habilidad del servicio IPRECON para producir soluciones económicas. Sin embargo, en los casos del acuerdo de cese de empleo, de los terrenos, y de la garantía, todos los clientes opinaban que las soluciones habían sido muy económicas. No puede ser determinado con la información disponible si las soluciones perjudicaron los intereses de terceros, la comunidad o la sociedad.

Lo vital de percibir es que, según su propia definición sobre calidad y las percepciones de los clientes entrevistados, el servicio conciliatorio de IPRECON ha logrado resultados de calidad, a pesar del contexto difícil (lo descrito en la primera sección) en que trabajan los conciliadores. Ningún cliente dijo que no usaría la conciliación otra vez y dos clientes afirmaron que, se surgieran conflictos, ellas recurrían a la conciliación. Estos éxitos demuestran la necesidad de proteger y desarrollar la conciliación como una institución valiosa que ya ha logrado y tiene la potencia de realizar aún más avances importantes en la resolución de conflictos.

\section{2. ¿Adónde vamos ahora?}

Si podemos evaluar al IPRECON con su definición de calidad, ¿cómo evaluaremos a otros centros de conciliación o a otros conciliadores?. ¿Es la estructura establecida por la ley y el reglamento suficiente o consideramos que las inconsistencias entre la ley y el reglamento, los estándares internacionales de mediación, y la definición de IPRECON sobre calidad señalan que la reforma es necesaria?.

Creemos que la ley y el reglamento no establecen una estructura adecuada para asegurar calidad, y que hay varios asuntos significativos que tienen que ser atendidos. En nuestra opinión, la mejor manera de hacerlo es a través de la difusión de un documento de discusión para los conciliadores, centros de conciliación, capacitadores, centros de capacitación, el Ministerio de Justicia y público en general. Proponemos que tal documento debería considerar los siguientes puntos: 
1. Si hay necesidad para una definición estandarizada de calidad en la conciliación extrajudicial, por encima de los contenidos de la ley y el reglamento;

2. Los elementos de dicha definición, cómo será aplicada, y cuales serían los valores enfatizados;

3. Qué realmente significa una "cultura de paz» en este contexto, y cómo podría ser lograda en el corto y largo plazo; y

4. Si se debe hacer cambios al sistema normativo conciliatorio actual o normar códigos de conducta (vinculantes o no vinculantes).

Como temas derivados de los arriba mencionados, creemos que estos puntos también deberían ser tratados:

1. La necesidad del conciliador por promover igualdad substantiva entre las partes (por ejemplo ¿cambia el deber del conciliador a favor de las partes según sus características individuales y el contexto?);

2. El rol

3. (o la falta de él) del conciliador en el logro de resultados justos;

4. Los requisitos de consentimiento informado y, cuánto y qué tipo de información puede brindar el conciliador a una o ambas partes;

5. Las obligaciones del conciliador y las partes hacia terceros y la influencia de estos intereses en las decisiones de las partes;

6. Cómo se puede mejorar la accesibilidad a la conciliación; y

7. Si la conciliación es total o predominantemente una institución mono-cultural..$^{68}$

68 A causa de la falta de espacio, fue imposible darle al muy importante asunto de la cultura en la resolución de conflictos la atención que merece. Sin embargo, vale mencionar que no hacer caso de la diversidad cultural crea el riesgo de que las posibilidades de enriquecer el discurso común puedan ser perdidas, y que también las instituciones de resolución de conflictos puedan ser vistas como ajenas y/o irrelevantes para los grupos minoritarios y, como consecuencia, serán poco utilizadas por dichos grupos. Para una discusión mayor de estos asuntos, consulte Joanna Drzewieniecki, Indigenous People, Law and Politics in Peri. State University of New York at Buffalo: Prepared for Delivery at the Meeting of the Latin American Studies Association, Washington, DC, September 28-30, 1995; Bruce E. Barnes, "Pacific Model Facilitation and Conferencing: Powerful tools for Preventing and Managing Ethnic Conflict» en: SIJ, Vol. 1, 1999, pp. 55-61; Ian Macduff, "Dispute Resolution Across Cultures" en: Peter Spiller, Dispute Resolution in New Zealand, Oxford University Press, London, 1999 ; Howard Gadlin, "Cultural Resolution, Cultural Differences, and the Culture of Racism.» en: Negotiation Journal, Vol. 10, 1994. 
Después de concluir este proceso, y si el consenso fuera posible, se puede publicar un manual para informar al público sobre la conciliación, que también puede auxiliarle a evaluar los servicios conciliatorios. El hecho que todos los clientes entrevistados supieran muy poco sobre la conciliación antes de asistir la audiencia, y fueron dependientes en ésta de sus abogados (quienes tal vez no fueron muy bien informados tampoco), señala que hay una necesidad de más educación pública sobre la conciliación.

Los clientes podrían estar mucho más informados si se diera un manual simple, escrito para el contexto peruano, a cada cliente antes de asistir la audiencia. Dicho manual podría exhibir una definición básica de la conciliación, sus beneficios y tal vez sus riesgos, y también el rol del conciliador y los de las partes. Idealmente, contendría información sobre el proceso de denuncia y sanción de conciliadores y centros de conciliación. El manual NADRAC, titulado $A$ Fair $S a y,{ }^{69}$ es un ejemplo excelente que podría ser seguido en el Perú. Aparte de brindar información sobre los roles del conciliador y las partes, A Fair Say también incluye discusiones cortas sobre temas como: «¿qué impide que funcione bien una sesión de mediación?», «çómo derrumbar barreras en una sesión», "género», «culturas distintas" $y$ «dinero, posición y autoridad?».

Si se diera a cada parte un manual único para todo el sistema, se aseguraría que cada una de ellas tuviera acceso a la misma cantidad y/o calidad de información. Además, podría facilitar que las audiencias sean más productivas, puesto que los clientes tendrían un mejor entendimiento de sus roles y la manera de comportarse para poder trabajar más constructivamente con la otra parte, desde el comienzo de la audiencia. Nos atrevemos a decir que esta información también sería relevante y útil no solo para los clientes, sino también para sus abogados.

69 NADRAC, A Fair Say: Managing Differences in Mediation and Conciliation. A Guide For All Involved, Canberra, NADRAC, 1999. 